\title{
Quantifying the Association Between Physical Activity and Injury in Primary School-Aged Children
}

\author{
Anneliese B. Spinks, BSc, BA a, Roderick J. McClure, MBBS, PhD'b, Chris Bain, MBBSa, Alison K. Macpherson, PhD ${ }^{c}$ \\ aSchool of Population Health, University of Queensland, Brisbane, Australia; bDepartment of Epidemiology and Community Care, School of Medicine, Griffith University, \\ Logan, Australia; 'SChool of Kinesiology and Health Science, York University, Toronto, Ontario, Canada \\ The authors have indicated they have no financial relationships relevant to this article to disclose.
}

\section{ABSTRACT}

BACKGROUND. Regular physical activity is strongly advocated in children, with recommendations suggesting up to several hours of daily participation. However, an unintended consequence of physical activity is exposure to the risk of injury. To date, these risks have not been quantified in primary school-aged children despite injury being a leading cause for hospitalization and death in this population.

OBJECT. Our goal was to quantify the risk of injury associated with childhood physical activity both in and out of the school setting and calculate injury rates per exposure time for organized and non-organized activity outside of school.

METHODS. The Childhood Injury Prevention Study prospectively followed a cohort of randomly selected Australian primary school- and preschool-aged children (4 to 12 years). Over 12 months, each injury that required first aid attention was registered with the study. Exposure to physical activity outside school hours was measured by using a parent-completed 7-day diary. The age and gender distribution of injury rates per 10000 hours of exposure were calculated for all activity and for organized and non-organized activity occurring outside school hours. In addition, child-based injury rates were calculated for physical activity-related injuries both in and out of the school setting.

RESULTS. Complete diary and injury data were available for 744 children. There were 504 injuries recorded over the study period, $396(88.6 \%)$ of which were directly related to physical activity. Thirty-four percent of physical activity-related injuries required professional medical treatment. Analysis of injuries occurring outside of school revealed an overall injury rate of 5.7 injuries per 10000 hours of exposure to physical activity and a medically treated injury rate of 1.7 per 10000 hours.

CONCLUSION. Injury rates per hours of exposure to physical activity were low in this cohort of primary school-aged children, with $<2$ injuries requiring medical treatment occurring for every 10000 hours of activity participation outside of school.

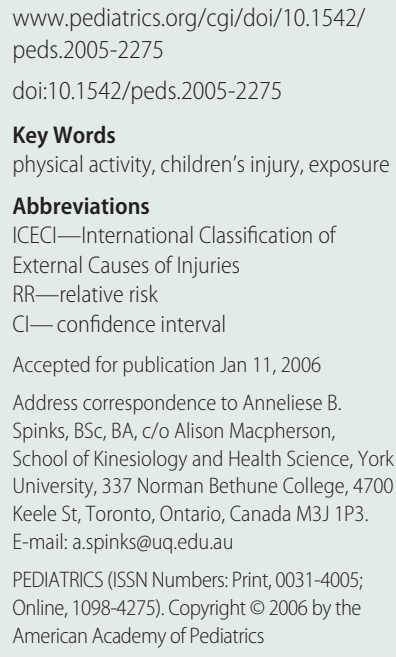


$\mathrm{R}$ EGULAR PHYSICAL ACTIVITY is important for children's overall health, providing a number of physical, social, and psychological benefits. ${ }^{1}$ Interventions to increase public participation in physical activity are advocated at all levels of government and policy, with Australian and other international guidelines recommending that children aged 5 to 12 years be active for at least 60 minutes and up to several hours every day..$^{2,3}$

However, an undesired consequence of some physical activity is exposure to the risk of injury. ${ }^{4,5}$ Injury is a leading cause of mortality and morbidity in Australian children, ${ }^{6}$ and a high percentage of childhood injuries occur while children are engaged in physical activity. ${ }^{7,8}$

Children are exposed to physical activity-related injuries in various physical and social environments, including during community organized sports, at school, and while engaging in non-organized active leisure pursuits such as bicycle riding, swimming, and playing. However, the true extent and patterns of the physical activityrelated injury problem are largely unknown. ${ }^{9,10}$ Exposure to activity is rarely included in estimates of injury incidence, and thus comparisons between various sociodemographic populations or environments are not possible.

In advocating for increased involvement of children in sport and physical recreation, it is important for public health practitioners to be aware of the magnitude of the adverse health consequences that may be involved. Our aim with this study was to quantify the risk of injury associated with childhood physical activity and compare this risk for age, gender, and socioeconomic subpopulations. This study was a component of a large cohort study, the Childhood Injury Prevention Study, conducted in Brisbane, Australia, in 2001-2004.

\section{METHODS}

\section{Study Design and Setting}

The Childhood Injury Prevention Study was a prospective cohort study involving a 12-month follow-up of Brisbane primary school-aged children. Brisbane is a metropolitan city on the east coast of Australia with 1.6 million inhabitants.

\section{Participant Recruitment}

Children were recruited continuously over 3 years by using a 2-tiered randomization process. Schools within the greater Brisbane area were allocated to 1 of 3 socioeconomic tiers (low, middle, and high) on the basis of their postal codes and then randomly selected for inclusion from these tiers. Up to 150 families with a child attending an included school were randomly selected by using random-number tables and invited to participate. Only 1 child per family was included; children in grade 7 were excluded because it was foreseen that over the course of the 1-year follow-up they would graduate into high school. If $>1$ child per family was eligible for inclu- sion, we used a quasi-random method to select which child to include. In these cases, we included the child with the most recent birthday at the time of interview. Given that the recruitment process was conducted throughout the entire year, this method did not lead to an oversampling of children with birthdays in any particular month.

\section{Variables, Instruments, and the Data-Collection Process}

There were 3 components of data collection for each child: a baseline home interview, a 7-day activity diary, and a record for each injury that occurred over 12 months. The baseline interview was conducted by a trained interviewer and lasted $\sim 45$ minutes. Age and gender details for the child were collected during the interview.

\section{Physical Activity-Exposure Measurement}

The activity diary provided a measure of exposure to physical activity. Parents were asked to describe the child's exact location and activity details for the entire day (with the exception of time spent at school). Mealtime prompts were given in the diaries to increase recall accuracy, ${ }^{11}$ and an example page was provided as a guide for the level of detail required. This activity diary was completed either before or soon after the baseline interview. Activities were coded according the International Classification of External Causes of Injuries (ICECI), ${ }^{12}$ which has been validated as a tool for assigning the following activity categories: paid and unpaid work, education, recreation and sport, sedentary leisure, transport, and vital activity (eg, sleeping, eating). The location of each activity was also coded by using the ICECI system. ${ }^{13}$

The total number of minutes per week spent in physical activity was calculated for each child on the basis of the assigned ICECI codes. We defined physical activity as all activities assigned to the categories of recreation and sport, paid and unpaid work in an outdoor location (eg, gardening, washing a car), and active means of transport (eg, walking, cycling).

In addition, the ICECI allows for the classification of sport and recreation activities into organized and nonorganized categories. We therefore calculate the total time for each child spent in organized and non-organized activity. Organized activities were those that fell under the auspice of a community or school administration and included pursuits such as community sports, dancing, and martial arts. All other activities fell into the non-organized category. Included in this category were active leisure pursuits, play, active transportation, and outdoor chores.

\section{Injury Data}

For each injury that occurred, a record was completed by either the participating family or a telephone interviewer. An injury was defined as any incident severe enough for first aid treatment to be sought. For the 
purposes of this study, a serious injury was defined as an injury for which professional health treatment was sought at an emergency department or by a general practitioner, dentist, or other health professional (eg, physiotherapist). At the time of the home interview, families were provided with an injury-event questionnaire along with a self-addressed envelope and instructed how to complete and return it to the study investigators if an injury occurred. Parents were contacted by telephone every 2 months after the initial interview to ensure that injuries sustained in that time were recorded. If an injury had occurred for which the study investigators had not received a completed injuryevent questionnaire, a telephone interview was conducted with the parent of the injured child to obtain and record the relevant information.

The injury-event questionnaire solicited information related to the location of the child and the circumstances surrounding the injury event. Details of the nature of the injury and place of treatment were also obtained. The questionnaires were coded using the same ICECI ${ }^{12}$ classifications used for the activity diaries.

\section{Data Analysis}

All analysis was conducted by using SPSS 12.0 (SPSS Inc, Chicago, IL). On the basis of the injury circumstances, each injury was categorized according to whether it was attributable to physical activity participation. Children were grouped into the following age groups: 4 to 6, 7 to 9, and 10 to 12 years. Socioeconomic category (low, middle, high) was assigned according to the school of attendance.

Accurate exposure estimates for physical activity during school were not available, so these injuries were analyzed separately. Population-based comparisons were made between children on the basis of yearly incidence of physical activity-related injuries occurring during and out of school.

For injuries occurring outside of school, injury rates per physical activity-exposure time were calculated. Numerators for injury rates were the number of injuries recorded in the database as having occurred over the course of the year. Calculations for exposure-specific rates were performed for each of the age, gender, and school SES categories using the formula below:

exposure-specific injury rate per 10000 hours $=$

No. of specified injuries $x$ $10000 \times 60$

person-minutes exposed to specified activity in the week $\times 52$

Comparisons were made across age, gender, and SES between the incidence of injuries for organized and non-organized activities.
Approval for the study was provided by the Queensland Department of Education and the Catholic Education Commission and the research ethics committee of the University of Queensland. Parental written consent was obtained for all participating children.

\section{RESULTS}

\section{Sample Characteristics and Physical Activity Participation}

The participant recruitment numbers and data obtained are shown in Table 1. During the recruitment phase of the study, 3507 children were invited to participate, of whom $871(25 \%)$ were subsequently registered in the cohort. The main reason for nonparticipation was parental refusal. In addition, a small number were not enrolled because the child was older than the age of interest to the study ( 12 years) or the family indicated they would be relocating away from the study area within the 12-month follow-up period.

Diaries were returned for 767 participants; however, only 744 were completed for the full week. All subsequent data analysis was conducted only for the 744 participants for whom complete diaries were returned. Of these diaries, 518 were completed to a predetermined standard during the normal school term while the child was healthy. Of the remaining diaries, 125 diaries coincided with either school or public holidays, the child was sick and did not attend school or normal activities in 33 diaries, and the child was in preschool and thus did not attend school for the whole week in 30 diaries. In addition, 41 diaries were not completed to a predetermined standard and hence contained some ambiguities. These diaries were included in the calculation of exposure to physical activity to account for illness and holidays that are expected to occur throughout the year and to increase statistical power of the study.

The sample characteristics and estimations of exposure to all physical activity and organized activity outside school hours are shown in Table 2. Being active in any way was significantly more common among boys than among girls, with a somewhat weaker relation existing for organized pastimes. Only exposure to organized sports varied notably with age, being markedly and significantly higher in children older than 7 years than for younger children. There were modest (nonsignificant) increases in exposure to organized sports with higher school SES.

\section{TABLE 1 Participant Enrollment}

\begin{tabular}{lc}
\hline & $N(\%)$ \\
\hline Invited to participate & 3507 \\
Enrolled in study & $871(25)$ \\
Returned diary & $767(22)$ \\
Returned complete diary (included in analysis) & $744(21)$ \\
\hline
\end{tabular}


TABLE 2 Sample Distribution of Exposure to Physical Activity Outside School Hours

\begin{tabular}{|c|c|c|c|c|}
\hline & $N$ & $\begin{array}{l}\% \text { of Total } \\
\text { Cohort }\end{array}$ & $\begin{array}{l}\text { Mean Physical Activity } \\
(95 \% \mathrm{Cl}), \mathrm{min} / \mathrm{wk}\end{array}$ & $\begin{array}{l}\text { Mean Organized Physical Activity } \\
(95 \% \mathrm{Cl}), \mathrm{min} / \mathrm{wk}\end{array}$ \\
\hline \multicolumn{5}{|l|}{ Age, y } \\
\hline 4-6 & 205 & 27.5 & 845 (787-903) & $76(60-92)$ \\
\hline $7-9$ & 326 & 43.8 & 906 (861-951) & $142(123-160)$ \\
\hline $10-12$ & 213 & 28.7 & 791 (735-847) & $160(133-188)$ \\
\hline \multicolumn{5}{|l|}{ Gender } \\
\hline Male & 407 & 54.7 & $909(867-950)$ & $142(125-160)$ \\
\hline Female & 337 & 45.3 & $792(749-835)$ & $113(96-130)$ \\
\hline \multicolumn{5}{|c|}{ School socioeconomic status } \\
\hline Low & 245 & 32.9 & $872(818-927)$ & $109(88-130)$ \\
\hline Middle & 240 & 32.3 & $811(761-862)$ & $133(111-154)$ \\
\hline High & 259 & 34.8 & $882(831-933)$ & $144(122-166)$ \\
\hline Total & 744 & 100 & $856(826-886)$ & $129(116-141)$ \\
\hline
\end{tabular}

\section{Overall Injury Incidence (Child Based)}

Over the study period, 504 separate injuries were reported for 315 children, representing a 12-month injury incidence of 67.7 per 100 children. Of the injuries, 167 (one third of the total) were serious and treated professionally, a 12-month incidence of 22.4 per 100 children.

\section{Physical Activity-Related Injuries (Child Based)}

Of the reported injuries, 396 (78.6\%) occurred while the child was physically active, giving a 12-month physical activity-related injury incidence of 53.2 per 100 children, with 18.1 per 100 classified as serious.

Nonspecified active play, both in and out of school, was the most common cause of physical activity-related injury. Specific activities with the highest numbers of injuries were soccer, bicycle riding, rugby, and scootering. For serious injury, the most common activities were soccer, bicycle riding, rugby, and tennis. The percentage of injuries treated professionally was not statistically different for injuries resulting from physical activity $(34.1 \%)$ compared with those resulting from other causes (burns, cuts, falls that were not related to physical activity, and assault [29.6\%]).

Boys were injured during physical activity more often than girls; the 12-month injury rate per 100 children was 62.9 and 41.5 for boys and girls, respectively (22.6 and 12.8, respectively, for serious injury). Age did not affect the overall incidence of physical activity-related injuries; however, older children aged 10 to 12 years sustained more serious injuries (12-month incidence: 23.6 per 100 children) than younger children aged either 4 to 6 years ( 15.6 per 100 children) or 7 to 9 years (16.3 per 100 children).

\section{Physical Activity-Related Injuries at School (Child Based)}

Eighty two of the physical activity-related injuries, 40 of which received professional medical treatment, occurred during school hours. The age and gender distributions of physical activity-related injuries that occurred both during school and outside of school are in shown in Table 3.
In the school setting, injury incidence showed a marked positive trend with age, with children aged 10 to 12 years sustaining more than twice as many serious injuries than younger children (relative risk [RR]: 2.38 [95\% confidence interval (CI): 1.32-4.30]). This pattern differed from that of injuries sustained outside of school, which did not show a relationship to age.

Boys were injured at only a slightly higher rate than girls in the school setting, but outside school, boys sustained more than twice as many serious injuries than did girls (RR: 2.16 [95\% CI: 1.41-3.32]).

Children attending low-SES schools seemed to sustain more injuries overall and more serious injuries at school than children attending middle- or high-SES schools did, although the difference was not statistically significant (RR for low versus high, respectively: 1.69 [95\% CI: 0.82-3.48] and 1.83 [95\% CI: 0.89-3.76]).

\section{Physical Activity-Related Injuries Outside of School (Exposure-Hours)}

The age and gender distribution for rates of injury per 10000 exposure hours across all activities, organized activities, and non-organized activities are shown in Table 4. Forty-six injuries ( $14.6 \%$ of the total) occurred to children who were engaged in organized sports or activity, and 20 of them were serious.

Overall, organized and non-organized physical activity rates were similar. However, serious injuries occurred more often during organized sports than during nonorganized activity (RR: 1.52 [95\% CI: 0.93-2.50]). This non-statistically significant difference was seen for both boys (RR: 1.53 [95\% CI: 0.86-2.71]) and girls (RR: 1.43 [95\% CI: $0.54-3.79]$ ) and in the 10- to 12-year age range (RR: 1.97 [95\% CI: 0.92-4.21]). The exception to this finding was in the youngest children aged 4 to 7 years.

Boys were consistently injured at a higher rate than girls for both organized and non-organized activity, even with exposure time taken into account. The difference was greater for more serious injury, with boys 
TABLE 3 Age, Gender, and School Socioeconomic-Status Distribution of Physical Activity-Related Total Injuries During and Outside of School

\begin{tabular}{|c|c|c|c|c|c|c|}
\hline & \multicolumn{2}{|c|}{ All Injuries } & \multicolumn{2}{|c|}{ School Injuries } & \multicolumn{2}{|c|}{ Non-School Injuries } \\
\hline & $\begin{array}{c}\text { No. of } \\
\text { Injuries }\end{array}$ & $\begin{array}{c}\text { Injury } \\
\text { Incidence }^{a}\end{array}$ & $\begin{array}{l}\text { No. of } \\
\text { Injuries }\end{array}$ & $\begin{array}{c}\text { Injury } \\
\text { Incidence }^{a}\end{array}$ & $\begin{array}{l}\text { No. of } \\
\text { Injuries }\end{array}$ & $\begin{array}{c}\text { Injury } \\
\text { Incidence }^{a}\end{array}$ \\
\hline \multicolumn{7}{|l|}{ All injuries } \\
\hline \multicolumn{7}{|l|}{ Age, y } \\
\hline 4-6 & 109 & 53.2 & 13 & 6.3 & 96 & 46.8 \\
\hline $7-9$ & 171 & 52.5 & 39 & 12.0 & 132 & 40.5 \\
\hline $10-12$ & 116 & 54.5 & 30 & 14.1 & 86 & 40.4 \\
\hline \multicolumn{7}{|l|}{ Gender } \\
\hline Male & 256 & 62.9 & 47 & 11.6 & 209 & 51.4 \\
\hline Female & 140 & 41.5 & 35 & 10.4 & 105 & 31.2 \\
\hline \multicolumn{7}{|c|}{ School socioeconomic status } \\
\hline Low & 133 & 54.3 & 30 & 12.2 & 103 & 42.0 \\
\hline Middle & 123 & 51.3 & 28 & 11.7 & 95 & 39.6 \\
\hline High & 140 & 54.1 & 24 & 9.3 & 116 & 44.8 \\
\hline Total & 396 & 54.1 & 82 & 11.0 & 314 & 42.2 \\
\hline \multicolumn{7}{|c|}{ Medically treated injuries } \\
\hline \multicolumn{7}{|c|}{ Age, y } \\
\hline $4-6$ & 32 & 15.6 & 7 & 3.4 & 25 & 12.2 \\
\hline $7-9$ & 53 & 16.3 & 14 & 4.3 & 39 & 12.0 \\
\hline $10-12$ & 50 & 23.5 & 20 & 9.4 & 30 & 14.1 \\
\hline \multicolumn{7}{|l|}{ Gender } \\
\hline Male & 92 & 22.6 & 24 & 5.9 & 68 & 16.7 \\
\hline Female & 43 & 12.8 & 17 & 5.0 & 26 & 7.7 \\
\hline \multicolumn{7}{|c|}{ School socioeconomic status } \\
\hline Low & 40 & 16.3 & 19 & 7.8 & 21 & 8.6 \\
\hline Middle & 44 & 18.3 & 11 & 4.6 & 33 & 13.8 \\
\hline High & 51 & 19.7 & 11 & 4.3 & 40 & 15.4 \\
\hline Total & 135 & 18.2 & 41 & 5.5 & 94 & 12.6 \\
\hline
\end{tabular}

requiring medical attention for injuries at nearly twice the rate as girls (RR: 1.89 [95\% CI: $1.20-2.96]$ ).

School SES did not affect overall injuries; however, children attending low-SES schools were less afflicted by serious injuries than children attending middle- (RR: 0.58 [95\% CI: $0.34-1.00]$ ) or high-SES schools (RR: 0.56 [95\% CI: $0.33-0.95])$.

\section{DISCUSSION}

We have quantified the likelihood of injury occurring during physical activity in Australian children aged 4 to 12 years by measuring exposure to activity and injury occurrence over 12 months. In addition, we have compared injury rates between organized and non-organized physical activity.

A high number of injuries sustained by the cohort $(88 \%)$ were directly related to physical activity. The annual incidence for children seeking medical treatment for a physical activity-related injury was 18 per 100 children. In terms of time exposure, nearly 6 injuries occurred for every 10000 hours of physical activity, with just under 2 of these requiring professional medical treatment.

Direct comparison between the benefits and harms of increased physical activity are not possible, because the benefits of physical activity in childhood are not readily quantifiable and often do not manifest until many years later. Nonetheless, with fewer than 2 injuries requiring professional medical treatment occurring for every 10000 hours of exposure to physical activity (about the average amount expected over 12 school years), the overall harms can be considered to be quite low compared with the possible benefits to be gained.

The finding that boys were injured at a higher rate than girls is consistent with injury-epidemiology literature, which has reported universally higher injury rates for boys in this age group. ${ }^{14}$

Approximately 20 percent of all physical activityrelated injuries occurred during school hours. Older children were more than twice as likely to sustain injuries requiring medical attention in this setting, whereas girls were nearly as likely to be injured as boys. Of particular note was the finding that the socioeconomic category of the school seemed to have an impact on the incidence of injuries in school that required medical attention, with children attending low-SES schools having an $80 \%$ greater risk of sustaining an injury requiring medical attention than those at high-SES schools. Although this might mean that schools in deprived neighborhoods pose more environmental hazards for children or are more poorly supervised, a possible alternative explanation could be that these children make up for lower 


\begin{tabular}{|c|c|c|c|c|c|c|}
\hline & \multicolumn{2}{|c|}{ All Activity } & \multicolumn{2}{|c|}{ Organized Activity } & \multicolumn{2}{|c|}{ Non-Organized Activity } \\
\hline & $\begin{array}{l}\text { No. of } \\
\text { Injuries }\end{array}$ & $\begin{array}{l}\text { Injury } \\
\text { Rate }^{a}\end{array}$ & $\begin{array}{l}\text { No. of } \\
\text { Injuries }\end{array}$ & $\begin{array}{l}\text { Injury } \\
\text { Rate }^{a}\end{array}$ & $\begin{array}{l}\text { No. of } \\
\text { Injuries }\end{array}$ & $\begin{array}{l}\text { Injury } \\
\text { Rate }\end{array}$ \\
\hline \multicolumn{7}{|l|}{ All injuries } \\
\hline \multicolumn{7}{|l|}{ Age, y } \\
\hline $4-6$ & 96 & 6.4 & 7 & 5.2 & 89 & 6.5 \\
\hline $7-9$ & 132 & 5.2 & 19 & 4.7 & 113 & 5.2 \\
\hline $10-12$ & 86 & 5.9 & 20 & 6.8 & 66 & 5.7 \\
\hline \multicolumn{7}{|l|}{ Gender } \\
\hline Male & 209 & 6.5 & 35 & 7.0 & 174 & 6.4 \\
\hline Female & 105 & 4.5 & 11 & 3.3 & 94 & 4.7 \\
\hline \multicolumn{7}{|c|}{ School socioeconomic status } \\
\hline Low & 103 & 5.6 & 11 & 4.8 & 94 & 5.8 \\
\hline Middle & 95 & 5.6 & 19 & 6.9 & 76 & 5.4 \\
\hline High & 116 & 5.9 & 16 & 5.0 & 100 & 6.0 \\
\hline Total & 314 & 5.7 & 46 & 5.9 & 268 & 5.7 \\
\hline \multicolumn{7}{|c|}{ Medically treated injuries } \\
\hline \multicolumn{7}{|c|}{ Age, y } \\
\hline 4-6 & 25 & 1.7 & 2 & 1.5 & 23 & 1.7 \\
\hline $7-9$ & 39 & 1.5 & 8 & 2.0 & 31 & 1.4 \\
\hline $10-12$ & 30 & 2.1 & 10 & 3.4 & 20 & 1.7 \\
\hline \multicolumn{7}{|l|}{ Gender } \\
\hline Male & 68 & 2.1 & 15 & 3.0 & 53 & 2.0 \\
\hline Female & 26 & 1.1 & 5 & 1.5 & 21 & 1.1 \\
\hline \multicolumn{7}{|c|}{ School socioeconomic status } \\
\hline Low & 21 & 1.1 & 3 & 1.3 & 18 & 1.1 \\
\hline Middle & 33 & 2.0 & 9 & 3.3 & 24 & 1.7 \\
\hline High & 40 & 2.0 & 8 & 2.5 & 32 & 1.9 \\
\hline Total & 94 & 1.7 & 20 & 2.4 & 74 & 1.6 \\
\hline
\end{tabular}

a Per 10000 hours of exposure.

organized sport participation outside by involving themselves in competitive activities at school, thus raising their injury-risk profile. School-activity participation was not measured, so it was not possible to test this hypothesis.

Outside of school hours, rates of injury requiring professional medical treatment per hours of exposure were slightly higher for organized than non-organized activity across the population except for in the youngest children aged 4 to 6 years. In the 10- to 12-year-old age range, this difference was nearly twofold. Previous research has reported higher injury rates in adolescent children than in children aged 12 years and under for a number of competitive sports. ${ }^{15}$ The increased injury rates among the older children in the current cohort indicates that the trend toward higher injury rates begins in the preadolescent years. Greater body mass and an increased competitive aggressiveness may account for this, as well as the possibility that older children are participating in more risky activities than younger children.

It is interesting to note that children from low-SES schools suffered from the fewest injuries outside school that required medical attention, even when exposure was taken into account. This finding may be partially explained by the economic and time costs related to seeking health care that may be less available to this population. Nonetheless, this finding is inconsistent with other literature, which has reported higher serious injury rates in disadvantaged populations, ${ }^{16,17}$ and with the finding in the current study that children attending lowSES schools received more serious injuries at school.

It is most likely that some activities have a higher injury-risk profile than others; however, this was not captured. Unspecified, spontaneous play, which is the most common way for children to be active, was responsible for the largest number of injuries in our sample. For activities that were specified, soccer, bicycle riding, rugby, and tennis caused the largest numbers of serious injuries. Additional work is required to calculate exposure-specific injury rates for these activities.

\section{METHODOLOGIC STRENGTHS AND LIMITATIONS}

There are a number of methodologic weaknesses that must be considered in the interpretation of these findings. The diary method for measuring exposure was of self-report-measure reliability. Despite this limitation, however, self-report techniques are the only feasible means for collecting exposure data for large samples, and prospective recording, as was done in the current study, has been shown to increase reliability. ${ }^{11}$ The ICECI, which was used to code the diaries, has been validated as a tool for assigning activity categories. ${ }^{13}$

A second limitation is that the week sampled may not 
have been typical for the child given that illness, weather, and school holidays may have impacted their activities for that week. Nonetheless, diaries were distributed evenly around the calendar year, and so summer and winter activities as well as school holidays were proportionately represented across the cohort population.

Injuries were also self-reported, which leaves open the possibility that some injuries may not have been reported to the study, although participants were contacted every 2 months by telephone in an attempt to minimize underreporting. In addition, willingness to seek medical attention may vary across participants, which may have impacted on our classification of "serious" injury.

A final methodologic weakness relates to the generalizability of the findings to the whole population. Only $25 \%$ of eligible children participated in the study, and injuries occurring to $15 \%$ of the participating cohort were not included because of the lack of physical activity-exposure data. Comparisons with census data from the school catchments imply that the more extreme levels of social disadvantage are not well represented in our sample (Christina Nagle, PhD, School of Population Health, University of Queensland, personal communication). Children with intellectual and physical disabilities, who may be at greater risk for injury, ${ }^{18}$ are also not represented.

The ability to measure exposure time for physical activity is the underlying strength of the study despite the limitations of the method used (mentioned above). Exposure data are necessary to accurately assess the risk of injury for a given activity; however, it is difficult to measure and is therefore often not available. ${ }^{15}$ Previous studies that have included exposure measurement have mostly concentrated on organized sports in competitive scenarios ${ }^{19-23}$ and therefore do not represent the majority of childhood physical activity that occurs in non-organized settings and environments.

An additional strength of this study is that we could include injuries that are not normally captured by traditional injury-surveillance techniques. Nearly two thirds of all injuries that received professional treatment were seen by a general practitioner or other health professional. Therefore, injury surveillance occurring in hospital emergency departments would fail to capture a significant number of physical activity-related injuries in this population.

\section{CONCLUSIONS}

Additional study should aim to capture more detailed in-school assessment of physical activity exposure to quantify the injury risk in this setting. The socioeconomic disparity in serious injury rates both in and out of the school setting also warrants additional investigation in a more highly powered study.
This study has shown that the injury risks for nonorganized physical leisure activities are similar to those for organized activities and thus are likely to account for a large proportion of the overall injury burden. Given that these activities occur in less controlled environments, greater challenges exist for the implementation of successful injury-reducing interventions.

\section{ACKNOWLEDGMENT}

This project was funded by the National Health and Medical Research Council of Australia.

\section{REFERENCES}

1. Physical Activity and Health: A Report of the Surgeon General. Atlanta, GA: US Department of Health and Human Services; 1996

2. Commonwealth Department of Health and Ageing. Australia's Physical Activity Recommendations for 5-12 Year Olds. Canberra, Australia: Commonwealth of Australia; 2004

3. Corbin CB, Pangrazi RP, Beighle A, Le Masurier G, Morgan C. Guidelines for Appropriate Physical Activity for Elementary School Children, 2003 Update. Reston, VA: National Association for Sport and Physical Education; 2003

4. Conn JM, Annest JL, Gilchrist J. Sports and recreation related injury episodes in the US population. Inj Prev. 2003;9:117-123

5. Williams JM, Wright P, Currie CE, Beattie TF. Sports related injuries in Scottish adolescents aged 11-15. Br J Sports Med. 1998;32:291-296

6. Australian Institute of Health and Welfare. Australia's Health 2002. Canberra, Australia: Australian Institute of Health and Welfare; 2002

7. Finch C, Valuri G, Ozanne Smith J. Sport and active recreation injuries in Australia: evidence from emergency department presentations. Br J Sports Med. 1998;32:220-225

8. Nolan T, Penny M. Epidemiology of non-intentional injuries in an Australian urban region: results from injury surveillance. $J$ Paediatr Child Health. 1992;28:27-35

9. Orchard JW, Finch CF. Australia needs to follow New Zealand's lead on sports injuries. Med J Aust. 2002;177:38-39

10. National Injury Prevention Advisory Council. Directions in Injury Prevention: Report 1-Research Needs. Canberra, Australia: Commonwealth Department of Health and Aged Care; April 1999

11. Baranowski T. Validity of children's self report of aerobic activity. Fam Health Proj Exerc Sport. 1984;55:309-317

12. International Classification of External Causes of Injuries Coordination and Maintenance Group. International Classification of External Causes of Injuries, version 1.2. Adelaide, Australia: Consumer Safety Institute, Amsterdam and AIHW National Injury Surveillance Unit; 2001

13. Steenkamp M, Harrison JE. International Classification of External Causes of Injuries Coordination: Case Scenario Testing. Canberra, Australia: Australian Institute of Health and Welfare; 2000

14. Emery CA. Risk factors for injury in child and adolescent sport: a systematic review of the literature. Clin J Sports Med. 2003; $13: 256-268$

15. de Loes M. Exposure data: why are they needed? Sports Med. 1997;24:172-175

16. Brown CE, Chishti P, Stone DH. Measuring socio-economic inequalities in the presentation of injuries to a paediatric $\mathrm{A} \& \mathrm{E}$ department: the importance of an epidemiological approach. Public Health. 2005; 1 19:721-725

17. Laing GJ, Logan S. Patterns of unintentional injury in childhood and their relation to socio-economic factors. Public Health. 1999;113:291-294 
18. Sherrard J, Tongue BJ, Ozanne-Smith J. Injury risk in young people with intellectual disability. J Intellect Disabil Res. 2002; $46: 6-16$

19. Maehlum S, Dahl E, Daljord OA. Frequency of injuries in a youth soccer tournament. Phys Sports Med. 1986;14:73-80

20. De Loes M, Goldie I. Incidence rate of injuries during sport activity and physical exercise in a rural Swedish municipality: incidence rates in 17 sports. Int J Sports Med. 1988;9:461-467
21. Durie RM, Munroe AD. A prospective survey of injuries in a New Zealand schoolboy rugby population. $N$ Z J Sports Med. 2000;28:84-90

22. Lindenfeld TN, Schmitt DJ, Hendy MP, Mangine RE, Noyes FR. Incidence of injury in indoor soccer. Am J Sports Med. 1994;22: 364-371

23. Schmidt-Olsen S, Bunemann LKH, Lade V, Brassoe JOK. Soccer injuries of youth. Br J Sports Med. 1985;19:161-164 